\title{
Maternal health care seeking behavior: the case of Haor (wetland) in Bangladesh
}

\author{
Md. Aminul Haque ${ }^{1 *}$, Surjya Kanta Dash ${ }^{1}$ and Muhammad Abdul Baker Chowdhury ${ }^{2}$
}

\begin{abstract}
Background: The state of maternal healthcare $(\mathrm{MHC})$ in Bangladesh is a grave concern especially in the remote haor areas. In this study, we aimed to determine the factors affecting the utilization of MHC services in the haor areas, to discover mothers' knowledge of $\mathrm{MHC}$, and explore their attitudes toward $\mathrm{MHC}$ as well as practices in seeking MHC services.

Method: In this cross-sectional survey $(n=400)$, we randomly selected mothers (aged 15-49 years) from haor areas of the Habiganj district of Bangladesh. The study participants' socio demographic information as well as the extent of their knowledge about MHC, their attitudes, and practices in seeking MHC services were ascertained. The degree of association between the respondents' socio-demographic characteristics and their health-seeking behavior (before, during, and after childbirth) was assessed by the odds ratio (OR) with $95 \%$ confidence intervals (Cl) estimated from the bivariate and multivariable logistic regression analyses.
\end{abstract}

Results: The mean age of the study participants was 27.26 years. Respondents had an average of 2.64 children, and $88.6 \%$ had at best a primary education or less. Among the study participants, $61 \%$ of mothers had no knowledge about the availability of $\mathrm{MHC}$ in the study area, and only $36 \%$ received any antenatal care (ANC). Also, $47 \%$ sought ANC from government healthcare institutions. Irrespective of complications and potential danger signs, $95 \%$ of births were delivered at home with the assistance of untrained birth attendants. Only $19.75 \%$ of mothers and 12. $3 \%$ of infants received postnatal care (PNC). Moreover, mothers who had a secondary or tertiary education level had a higher likelihood of receiving ANC (OR: 3.48, 95 \% C.I: 1.49-7.63) compared to mothers with no education. Also, mothers aged 25 years or older were less likely (OR: 0.24, $95 \%$ C.I: 0.06-0.095) to give birth in a health facility than mothers who were younger than 25. The low utilization of MHC services can be attributed to many factors such as a lack of communication, a lack of knowledge about MHC services, low income, decision making, and the lack of a companion with whom to visit health services.

Conclusion: To improve MHC utilization, to reach national targets and to save the lives of mothers and newborns, boat or ship-based special healthcare and educational programs should be implemented in the haor areas.

Keywords: Maternal health care (MHC), Antenatal care (ANC) services, Postnatal care (PNC), Hoar areas, Bangladesh

\section{Background}

Maternal mortality ratio (MMR) of a country is an important indicator of the overall health status of its mothers. Similar to other developing countries, in Bangladesh, high MMR epitomizes the end point in a lifetime experience in which women encounter gender discrimination, societal neglect and deprivation. Also, high MMR signifies the weakness of the health system to provide effective services

\footnotetext{
* Correspondence: aminul.haque@du.ac.bd

'Department of Population Sciences, University of Dhaka, Dhaka 1000, Bangladesh

Full list of author information is available at the end of the article
}

and care for the population. The target of the fifth Millennium Development Goal (MDG-5) for Bangladesh was to reduce MMR by 75 \% between 1990 and 2015 (i.e. to reduce the MMR to 143 deaths per 100,000 live births). Bangladesh has experienced a gradual decline in its MMR over the past decades, from 500 in 1990 to 194 in 2010 [1]. However, the ratio remains unacceptably high $[2,3]$. The government is committed to improving the maternal health situation in the country by adopting special strategies such as the Safe Motherhood Promotion Project (SMPP) [4]. However, the situation remains critical due to 
inadequate access to healthcare and poor utilization of modern health services. Despite the government's serious commitment to deliver health facilities to people's doorsteps through innovative approaches, such as the Essential Service Package (ESP), the utilization of health services is still far below any acceptable standard. Bangladesh did not meet the MDG- 5 by the target year, 2015.

Wide disparities exist in the utilization of MHC services between different geographic regions in Bangladesh. According to the 2010 Bangladesh Maternal Mortality Survey Report, the MMR in urban and rural areas was 178 and 198, respectively, with a national average of 194 [5]. These numbers are quite indicative because Bangladesh is essentially an agrarian country with two-thirds of its total population living in rural areas, however, this is one of the highest MMR indicators in the world [6]. Furthermore, approximately $75 \%$ of the babies born to these rural women also die within the first week of their lives [7]. Because modern health services are not equally accessible throughout the diverse geographic areas in the country (e.g. plain, hilly, forest, marshy, or coastal areas), the regional variation in the MMR is striking. For example, in 2010, the MMR in the marshland-dominated northeastern Sylhet Division, was nearly seven times higher (425) than that in the southwestern Khulna Division (64) [5]. The Sylhet division consists of a large number of haors which are huge bowl-shaped tectonic depressions that receive surface runoff water during the monsoon. Typically, the low-lying plain land in a haor area remains submerged under water for more than six months a year, and during this period, these areas remains completely unreachable. A large area in the eastern part of Bangladesh has been classified as haor. Excessive precipitation, flood, and storms in these areas severely affects human life and movement.

\section{Maternal mortality}

Addressing maternal mortality, i.e. the death of a woman during pregnancy or within the first 42 days of post-partum period due to causes directly or indirectly associated with the pregnancy, has been a priority for the global health and development community since the Nairobi Safe Motherhood Conference in 1987 [8]. This conference was followed by numerous international forums at which safe motherhood has always been on the agenda. As a consequence, in 2000 the Millennium Summit of the United Nations set the improvement of maternal health as one of the eight Millennium Development Goals (MDGs) [9]. Accordingly, the MMR, a significant indicator of the overall health status of women in a country, has now become an essential development indicator around the world.

Over the decades, Bangladesh has made some progress in improving maternal and child health. For example, MMR dropped from 570 per 100,000 live births in $1990-91$ to
194 per 100,000 live births in 2010 [5, 10]. Similarly, ANC coverage (at least one visit) increased from $27.5 \%$ in 199394 to $58.7 \%$ in 2012-13 [11, 12]. But this progress was not enough to achieve the MDG-5 targets in 2015. The Bangladesh government was committed to achieving the Millennium Development Goal (MDG) for maternal mortality through reducing the MMR by three-quarters by the year 2015' from 1990 levels [10, 13] and is now preparing to address the Sustainable Development Goals 3.1 (SDGs). To lower the national MMR, there is an urgent need to develop effective and affordable programs that ensure proper utilization of MHC services for every woman in the country, especially in the rural areas. Attaining this ambitious goal requires the strengthening of preventive interventions at the community level, ensuring high-quality basic and comprehensive obstetric care, and promoting timely careseeking from these facilities for maternal emergencies [14].

Care seeking is in many ways the cornerstone of maternal mortality reduction efforts, yet research into how to best promote care seeking in different settings is lacking $[15,16]$. The concept of 'care seeking' has often been defined in narrow terms in maternal health, with 'care' denoting services provided by professionals with appropriate lifesaving skills, and 'seeking' denoting transfer of the woman from the home to a health facility [17]. In a recent national survey on maternal health in Bangladesh, the majority of women reported complications during pregnancy and childbirth, but few reported that they sought care from medically trained providers in health facilities, even when they perceived the complication to be life threatening. Most women reported that they accessed MHC in the home or sites other than designated health centers and facilities [18]. Despite the best efforts of the government to deliver healthcare services to people, the situation of pregnancy and childbirth related morbidity and mortality is worse in Bangladesh because of low utilization of maternal health services in remote areas [19].

\section{MHC delivery system in Bangladesh}

The largest part of the country's health infrastructure and health service system is established under the government's management and supervision. The Ministry of Health and Family Welfare (MOHFW) is responsible for comprehensive health policy formulation, planning and decision making in Bangladesh. There are two implementation wings under MOHFW: (i) Directorate General of Health Services (DGHS) and (ii) Directorate General of Family Planning (DGFP). The DGHS and DGFP are responsible for implementing all health programs and family planning programs, respectively. Despite having a large population living in a small area, Bangladesh's public health system is quite well organized. The health service delivery system in the public sector is divided into primary, secondary and tertiary levels. 
The first contact rural populations have with public health services is in their homes. As the administrative hierarchy rises, the level and sophistication of health services also increase.

A number of studies have been conducted into the difference between MHC utilization in urban and rural areas, but no study has focused exclusively on $\mathrm{MHC}$ in the haor areas [17, 20-23]. Because of the adverse natural and geographical characteristics of the haor region, the community has to adopt differentiated healthcare seeking approaches. This study can provide the government and/or nongovernment service providers with detailed information about formulating effective strategies to attain the SDG by reducing MMR. In this context, the study aimed to determine mothers' knowledge about MHC services, the pattern of MHC seeking behavior, and factors affecting the utilization of MHC services in the haor area.

\section{Methods \\ Study sample}

We conducted a cross-sectional study among 400 women age 15-49 years living in two Unions ${ }^{1}$ of the north-eastern Hobigonj District of Sylhet division of Bangladesh who had had at least one live birth in the 5 years preceding the study. The study area and the study participants were selected through a multi-stage random sample procedure. In the first stage, Habiganj district was selected randomly from the six districts of Sylhet Division where haors are located. In the second stage, Ajmirignaj Upazila (a third level government administrative unit) was selected from the Habiganj district as this unit only contains haor area. In the third stage, two Unions (local level government administrative units) Ajmiriganj Sadar and Shibpasha were selected randomly from the five Unions of Ajmirignaj Upazila. The list of the total number of married couples having at least one child was prepared with the help of Family Welfare Assistants (FWAs) working in the Unions. The total number of married couples listed in Ajmiriganj Sadarunion and Shibpasha Union was 3240 and 3143, respectively. Then, from each union, 200 married women aged 15-49 years who had experienced at least one pregnancy in the preceding 5 years of the study were randomly selected. The sample size was calculated using the standard formula, assuming the total population size being greater than 10,000. The proportion of married women aged between 15 and 49 with respect to the total female population was $0.34(p=0.34)$, so $\mathrm{q}=0.66$. We set a standard normal deviation at 1.96 corresponding to a $95 \%$ confidence interval and a design effect of 1.0. Using the distribution of the population, the required representative sample size was 345. A total of 400 women (200 from each Union) were interviewed using a semi-structured questionnaire.

\section{Data collection}

Four female research assistants and one supervisor were recruited and trained at the Department of Population Sciences, University of Dhaka, Bangladesh. These four research assistants were involved in the process of the development of the data collection tools, so that they could understand the rationale and theme of each concept and the purpose of the study. All research assistants received training on rapport building, ensuring privacy, confidentiality, and social and cultural sensitivity during data collection. One supervisor was recruited for each Union to lead the data collection process and to resolve any issues related to the data collection. The research assistants described the study purpose and procedures to the study participants, asked for oral consent and enrolled them into the study. The research assistants conducted face-to-face interviews for approximately $1 \mathrm{~h}$ with standardized pre tested questionnaires and obtained information on socioeconomic and demographic characteristics, their knowledge of MHC services availability, service delivery schedules, payments mode, ANC, delivery and PNC. The main field work for data collection started on January 01, 2009 and ended on February 15, 2009. The supervisor was present in the field full-time to monitor and ensure the quality of the data collection. All of the information was de-identified before the analyses.

\section{Data analysis}

We checked variables for accuracy and calculated descriptive statistics for age groups, number of children, type of family, husbands' occupation, household monthly income and education level of participants and their husbands. A chi-square test was performed for ANC and PNC by demographic, socioeconomic, and different types of service providers. We employed binary logistic regression to assess the correlates ANC, place of delivery and assistance at delivery with mother's age at last birth, birth order, mother's education, husband's education, monthly family income, and husband's occupation. Odds ratios (OR) with $95 \%$ confidence intervals (CI) were estimated. Model adequacy was checked using the Chi-square value of the Hosmer Lomshow test. We also examined the value of 2 Log Likelihood ratio test, AIC, and the area under the receiver operating characteristic (ROC) curve. Data was analyzed using the Statistical Package for the Social Sciences (Version SPSS-12.0 and SPSS-15.0), and considered twosided inference tests with an alpha $<0.05$ as statistically significant.

\section{Results}

The distribution of the socio-demographic characteristics of the respondents is presented in Table 1 . The mean age of the respondents was 27.62 years. Approximately $37.8 \%$ had no formal education and $50.8 \%$ of 
Table 1 Distribution of the respondents by their sociodemographic characteristics

\begin{tabular}{|c|c|c|c|}
\hline Categories & Frequency & Percent & \multirow{8}{*}{$\begin{array}{l}\text { Mean age : } 27.62 \\
\text { Years; }\end{array}$} \\
\hline $15-19$ & 33 & 8.3 & \\
\hline $20-24$ & 100 & 25.0 & \\
\hline $25-29$ & 133 & 33.3 & \\
\hline $30-34$ & 84 & 21.0 & \\
\hline $35-39$ & 45 & 11.3 & \\
\hline $40+$ & 5 & 1.3 & \\
\hline Total & 400 & 100.0 & \\
\hline \multicolumn{4}{|l|}{ Number of children } \\
\hline 1 & 87 & 21.8 & \\
\hline 2 & 101 & 25.3 & \multirow{6}{*}{$\begin{array}{l}\text { Mean number of } \\
\text { children:2.64/ } \\
\text { household }\end{array}$} \\
\hline 3 & 118 & 29.5 & \\
\hline 4 & 60 & 15.0 & \\
\hline 5 & 31 & 7.8 & \\
\hline $6+$ & 3 & 0.8 & \\
\hline Total & 400 & 100.0 & \\
\hline \multicolumn{4}{|l|}{ Type of family } \\
\hline Nuclear family & 84 & 21.0 & \\
\hline Extended family & 316 & 79.0 & \\
\hline Total & 400 & 400 & \\
\hline \multicolumn{4}{|c|}{ Number of family member } \\
\hline Less than 5 & 106 & 26.5 & \\
\hline $6-8$ & 265 & 66.3 & \multirow[t]{3}{*}{ Mean: 6.42} \\
\hline $9+$ & 29 & 7.3 & \\
\hline Total & 400 & 100.0 & \\
\hline
\end{tabular}

Occupation of the husband of the respondents

$\begin{array}{lll}\text { Agriculture } & 118 & 29.5 \\ \text { Day Laborer } & 137 & 34.3 \\ \text { Small business } & 120 & 30.0 \\ \text { Service } & 18 & 4.5 \\ \text { Other } & 7 & 1.8 \\ \text { Total } & 400 & 100\end{array}$

Monthly income (TK)

\begin{tabular}{|c|c|c|c|c|}
\hline $2000-4000$ & & 256 & 64.0 & \\
\hline \multicolumn{2}{|l|}{$4000-6000$} & 93 & 23.3 & Mean: 4339.25 \\
\hline \multicolumn{2}{|l|}{$6000-8000$} & 36 & 9.0 & \\
\hline \multicolumn{2}{|l|}{$8000-10,000$} & 7 & 1.8 & \\
\hline \multicolumn{2}{|l|}{$10,000-12,000$} & 8 & 2.0 & \\
\hline \multicolumn{2}{|l|}{ Total } & 400 & 100.0 & \\
\hline \multirow{2}{*}{$\begin{array}{l}\text { evel of } \\
\text { education }\end{array}$} & \multicolumn{2}{|l|}{ Respondent } & \multicolumn{2}{|c|}{ Husband of respondent } \\
\hline & Frequency & Percent & Frequency & Percent \\
\hline $\begin{array}{l}\text { No } \\
\text { ducation }\end{array}$ & 151 & 37.8 & 135 & 33.8 \\
\hline
\end{tabular}

Table 1 Distribution of the respondents by their sociodemographic characteristics (Continued)

\begin{tabular}{lllll}
\hline $\begin{array}{l}\text { Primary } \\
(1-5)\end{array}$ & 203 & 50.8 & 219 & 54.8 \\
$\begin{array}{l}\text { Secondary } \\
(6-10)\end{array}$ & 39 & 9.8 & 34 & 8.5 \\
$\begin{array}{l}\text { Higher } \\
\text { Secondary }\end{array}$ & 7 & 1.8 & 5 & 1.3 \\
$\begin{array}{l}(11-12) \\
\text { Graduation }\end{array}$ & - & - & 7 & 1.8 \\
Total & 400 & 100.0 & 400 & 100.0 \\
\hline
\end{tabular}

the respondents had between 1 and 5 years of schooling. Around $30 \%$ of respondents' husbands were involved in agricultural activities and $34.3 \%$ were day laborers. The mean household income of the respondents was BDT4339.25 per month (1US\$ $1=$ BDT 79.5 in 2015) for a mean household size of 6.42 people.

It was observed that only $36 \%$ of women who gave birth in the 5 years preceding the survey received at least one instance of ANC from any source. Also, among the women who received ANC, $47.9 \%$ of them sought it from government healthcare institutions i.e. Upazila Health Complex or Union Family Welfare Centre (Table 2). It was observed from the study that only $13.8 \%$ of women who experienced birth in the 5 years preceding the survey received PNC following their last birth. Findings show that only $12.3 \%$ of infants received PNC (Table 2).

Table 2 Distribution of respondents by Antenatal Care Visits, sources of ANC, providers and place of delivery

\begin{tabular}{lll}
\hline Characteristics & Frequency & Percent \\
\hline Antenatal care visits at the time of last pregnancy & \\
Yes & 144 & 36.0 \\
No & 256 & 64.0 \\
Total & 400 & 100 \\
Source of antenatal care & & \\
Government health care institutions & 69 & 47.9 \\
Pharmacy & 28 & 19.4 \\
Quack & 47 & 32.6 \\
Total & 144 & 100.0 \\
Place of delivery & & \\
Home & 380 & 95.0 \\
Health facility & 20 & 5.0 \\
Total & 400 & 100.0 \\
Post-natal care for mothers $(n=400)$ & & 13.8 \\
Yes & 55 & 12.3 \\
Post-natal care for child $(n=400)$ & & \\
Yes & 49 & \\
\hline
\end{tabular}


The three main reasons for receiving ANC were headache (21\%), abdominal pain (32.7\%), and excessive vomiting (27. $2 \%$ ). The main reasons for not seeking ANC in a facility were high cost (24.8\%), lack of money (26.8\%), remote location (7.4\%) and bad transportation (20.0\%) (Table 3). The study findings showed $95 \%$ of deliveries occurred in the home, and only $5 \%$ (20) of deliveries occurred at health centers (Table 3 ).

The bivariate analysis shows that receiving ANC was significantly associated with the socio-economic and demographic variables like mother's age at birth, birth order, mother's education, husband's education and occupation, and household family income (Table 4). Moreover, mother's age at birth, birth order, and mother's education was significantly associated with type of ANC provider (Table 5).

The analysis also shows that, mother's age at birth, type of family, and birth order were significantly associated with determining place of delivery, as well as the type of assistance during delivery (Table 6). Younger mothers, educated mothers, and mothers with husbands with higher a level of education received more PNC (Table 7). The majority of the respondents (85\%) opined that a PNC check-up was not needed.

Table 8 shows the results from the logistic regression analysis with $95 \%$ confidence interval for the use of

Table 3 Distribution of respondents by problems for which they did and did not sought ANC

\begin{tabular}{llll}
\hline Problems & \multicolumn{2}{l}{ Response } & $\begin{array}{l}\text { Percent } \\
\text { of cases }\end{array}$ \\
\cline { 2 - 3 } & $\mathrm{N}$ & Percent & \\
\hline Reason for seeking ANC & & & \\
Regular check-up & 10 & 3.7 & 6.8 \\
Headache & 57 & 21.0 & 38.8 \\
High blood pressure & 11 & 4.0 & 7.5 \\
Tetanus & 9 & 3.3 & 6.1 \\
Abdominal pain & 89 & 32.7 & 60.5 \\
Injury & 17 & 6.3 & 11.6 \\
Excess vomiting & 74 & 27.2 & 50.3 \\
Other & 5 & 1.8 & 3.4 \\
Total & 272 & 100.0 & 185.0 \\
Reason for not seeking ANC & & & \\
Lack of need of ANC services & 66 & 10 & 26.1 \\
Expensive & 164 & 24.8 & 64.8 \\
Lack of money & 177 & 26.8 & 70.0 \\
Too far/distance & 48 & 7.3 & 19.0 \\
Problem with transportation & 125 & 18.9 & 49.4 \\
Lack of companion & 10 & 1.5 & 4.0 \\
No permission from family & 70 & 10.6 & 27.7 \\
Total & 660 & 100.0 & 260.9 \\
\hline
\end{tabular}

${ }^{\mathrm{a}}$ Multiple responses
Table 4 Socio-demographic profile by antenatal care received

\begin{tabular}{|c|c|c|c|c|c|c|}
\hline \multirow[t]{3}{*}{ Characteristics } & \multicolumn{4}{|c|}{ Antenatal care received } & \multirow{3}{*}{$\begin{array}{l}\text { Total } \\
(\mathrm{N})\end{array}$} & \multirow[t]{3}{*}{$p$-values } \\
\hline & \multicolumn{2}{|l|}{ Yes } & \multicolumn{2}{|l|}{ No } & & \\
\hline & $\mathrm{n}$ & $\%$ & $\mathrm{n}$ & $\%$ & & \\
\hline \multicolumn{7}{|l|}{ Mothers age at birth } \\
\hline Less than 25 & 66 & 49.6 & 67 & 50.4 & 133 & \\
\hline $25-29$ & 45 & 33.8 & 88 & 66.2 & 133 & 0.000 \\
\hline $30-34$ & 27 & 32.1 & 57 & 67.9 & 84 & \\
\hline More than 35 & 6 & 12.0 & 44 & 88.0 & 50 & \\
\hline \multicolumn{7}{|l|}{ Birth Order } \\
\hline 1 & 48 & 55.2 & 39 & 44.8 & 87 & \\
\hline 2 & 36 & 33.6 & 65 & 64.4 & 101 & 0.000 \\
\hline 3 & 41 & 34.7 & 77 & 65.3 & 118 & \\
\hline 4 & 19 & 20.2 & 75 & 79.8 & 94 & \\
\hline \multicolumn{7}{|l|}{ Type of family } \\
\hline Nuclear family & 13 & 35.1 & 24 & 64.9 & 37 & \\
\hline Extended family & 131 & 36.1 & 232 & 63.9 & 363 & 0.908 \\
\hline \multicolumn{7}{|l|}{ Mother's education } \\
\hline No education & 38 & 25.2 & 113 & 74.8 & 151 & \\
\hline Primary & 71 & 35.4 & 132 & 65.0 & 203 & 0.000 \\
\hline Secondary and more & 35 & 76.1 & 11 & 23.9 & 46 & \\
\hline \multicolumn{7}{|l|}{ Husband's education } \\
\hline No education & 32 & 23.7 & 103 & 76.3 & 135 & \\
\hline Primary & 81 & 37.0 & 138 & 63.0 & 219 & 0.001 \\
\hline Secondary and more & 31 & 67.4 & 15 & 32.6 & 46 & \\
\hline \multicolumn{7}{|l|}{ Husband's occupation } \\
\hline Agriculture & 40 & 33.9 & 78 & 66.1 & 118 & \\
\hline Laborer & 31 & 22.6 & 106 & 77.4 & 137 & \\
\hline Small business & 55 & 45.8 & 65 & 54.2 & 120 & 0.000 \\
\hline Service & 14 & 77.8 & 4 & 22.2 & 18 & \\
\hline Others & 4 & 57.1 & 3 & 42.9 & 7 & \\
\hline \multicolumn{7}{|l|}{ Family income } \\
\hline $2000-4000$ & 81 & 31.6 & 175 & 68.4 & 256 & \\
\hline $4000-6000$ & 36 & 38.7 & 57 & 61.3 & 93 & 0.000 \\
\hline $6000-8000$ & 18 & 50.0 & 18 & 50.0 & 36 & \\
\hline More than 8000 & 9 & 60.0 & 6 & 40.0 & 15 & \\
\hline
\end{tabular}

ANC. Only mothers' education level was found to be a significant predictor of receiving ANC adjusted by other covariates. Mothers who have primary education were 3.38 (95 \% CI: 1.39, 8.70) times more likely to receive ANC compared to the mothers without education. Similarly, mothers with secondary education had higher odds (OR: 3.48, 95 \% CI: 1:50, 7.63) of receiving ANC compared to the mothers without education. No association was observed for mother's age at birth, birth order, husband's education, family income and/ or husband's occupation. 
Table 5 Background characteristics of participants who received ANC by different type of provider

\begin{tabular}{|c|c|c|c|c|c|c|c|c|}
\hline \multirow[t]{3}{*}{ Background characteristics } & \multicolumn{4}{|c|}{ Medically trained providers } & \multirow{2}{*}{\multicolumn{2}{|c|}{$\begin{array}{l}\text { Non-trained } \\
\text { provider }\end{array}$}} & \multirow{3}{*}{$\begin{array}{l}\text { Total } \\
(N)\end{array}$} & \multirow[t]{3}{*}{$p$-values } \\
\hline & \multicolumn{2}{|c|}{ MBBS doctor } & \multicolumn{2}{|c|}{ Nurse/paramedic } & & & & \\
\hline & $\mathrm{N}$ & $\%$ & $\mathrm{~N}$ & $\%$ & $\mathrm{~N}$ & $\%$ & & \\
\hline \multicolumn{9}{|l|}{ Mother's age at birth } \\
\hline Young aged mother ( $\leq 25$ years) & 23 & 34.8 & 29 & 43.9 & 14 & 21.2 & 66 & 0.022 \\
\hline Old aged mother ( $>25$ years) & 17 & 21.8 & 28 & 35.9 & 33 & 42.3 & 78 & \\
\hline \multicolumn{9}{|l|}{ Birth order } \\
\hline 1 & 21 & 43.8 & 18 & 37.5 & 9 & 18.8 & 48 & \\
\hline 2 & 6 & 16.7 & 18 & 50.0 & 12 & 33.3 & 36 & 0.038 \\
\hline 3 & 9 & 22.0 & 15 & 36.6 & 17 & 41.5 & 41 & \\
\hline 4 & 4 & 21.1 & 6 & 31.6 & 9 & 47.4 & 19 & \\
\hline \multicolumn{9}{|l|}{ Type of family } \\
\hline Nuclear family & 4 & 30.8 & 7 & 53.8 & 2 & 15.4 & 13 & \\
\hline Extended family & 36 & 27.5 & 50 & 38.2 & 45 & 34.4 & 131 & 0.353 \\
\hline \multicolumn{9}{|l|}{ Mother's education } \\
\hline No education & 5 & 13.2 & 17 & 44.7 & 16 & 42.1 & 38 & \\
\hline Primary & 17 & 23.9 & 29 & 40.8 & 25 & 35.2 & 71 & 0.005 \\
\hline Secondary and more & 18 & 51.4 & 11 & 31.4 & 6 & 24.3 & 35 & \\
\hline \multicolumn{9}{|l|}{ Husband's education } \\
\hline No education & 6 & 18.8 & 10 & 31.3 & 16 & 50.0 & 32 & \\
\hline Primary & 23 & 28.4 & 33 & 40.7 & 25 & 30.9 & 81 & 0.128 \\
\hline Secondary and more & 11 & 35.5 & 14 & 45.2 & 6 & 19.4 & 31 & \\
\hline
\end{tabular}

$p$-values obtained from Chi-Squire test

The results also show that only mother's age was significantly associated with predicting the place of delivery. It was found that, mothers aged 25 years and older were less likely (OR: $0.24,95 \%$ CI: $0.06,0.95)$ to give birth in a healthcare facility than the mothers who are less than 25 years of age (Table 9). Neither birth order nor family type had influence on predicting the place of delivery.

Similar to the place of delivery, only mothers' level of education was significantly associated with predicting assistance during delivery. It was found that mothers with primary (OR: $0.48, \mathrm{CI}: 0.18,0.95)$, secondary or tertiary (OR: $0.41,95 \%$ CI: $0.22,0.97$ ) were less likely to give birth assisted by a traditional birth attendant compared to mothers with no education. Mothers age at last birth, birth order, and/ or family type (nuclear vs. extended) had no influence on the prediction of assistance at the time of delivery (Table 10).

\section{Discussion}

All the survey respondents were rural people of a geographically adverse area, with little formal education whose livelihood is mainly based on agriculture. Haors occupy a large portion of Bangladesh, and this region is typically inaccessible, with the plains being submerged under water for more than 6 months of the year, causing transport and communication facilities to become very poor. The study found that among ANC receivers half of the women seek ANC from government healthcare institutions, i.e. Upazila Health Complex or Union Family Welfare Centre. This percentage is lower than the national average for rural women of Bangladesh who received ANC from government facilities [3]. Receiving ANC services from medically trained personnel is very important for the wellbeing of mothers and new-born children. The number of ANC visits and the timing of the first check-up are both considered important in detecting and preventing an adverse pregnancy outcome. As per the World Health Organization (WHO) standard, every pregnant woman should receive ANC within the first trimester irrespective of any problem faced by them. This study's survey respondents only seek ANC when they face a particular problem, and the percentage is very low $(6.8 \%)$ compared to the national average. This may be due to low level of education, lack of awareness, etc. Moreover, the study also found that a lack of money is the prominent reason for not seeking ANC. This finding is supported by the low economic status of the respondents.

Half of the respondents mentioned transportation problems as a reason for not seeking ANC. In the study 
Table 6 Place of delivery according to background characteristics

\begin{tabular}{|c|c|c|c|c|c|c|}
\hline \multirow[t]{2}{*}{ Background characteristics } & \multicolumn{2}{|c|}{ Home } & \multicolumn{2}{|c|}{ THC/ UFWC } & \multirow{2}{*}{$\begin{array}{l}\text { Total } \\
(\mathrm{N})\end{array}$} & \multirow[t]{2}{*}{ P-Value } \\
\hline & $\mathrm{N}$ & $\%$ & $\bar{N}$ & $\%$ & & \\
\hline Mother's age at birth & & & & & & 0.000 \\
\hline Young aged mother $(\leq 25)$ & 117 & 88.0 & 16 & 12.0 & 133 & \\
\hline Old aged mother $(>25)$ & 263 & 98.5 & 4 & 1.5 & 267 & \\
\hline Birth Order & & & & & & 0.000 \\
\hline 1 & 74 & 85.1 & 13 & 14.9 & 87 & \\
\hline 2 & 97 & 96.0 & 4 & 4.0 & 101 & \\
\hline 3 & 117 & 99.2 & 1 & 0.8 & 118 & \\
\hline 4 & 92 & 97.9 & 2 & 2.1 & 94 & \\
\hline Type of family & & & & & & 0.001 \\
\hline Nuclear family & 31 & 83.8 & 6 & 16.2 & 37 & \\
\hline Extended family & 349 & 96.1 & 14 & 3.9 & 363 & \\
\hline Mother's education & & & & & & 0.111 \\
\hline No education & 143 & 94.7 & 8 & 5.3 & 151 & \\
\hline Primary & 196 & 96.6 & 7 & 3.4 & 203 & \\
\hline Secondary and more & 41 & 89.1 & 5 & 10.9 & 46 & \\
\hline Husband's education & & & & & & 0.301 \\
\hline No education & 127 & 94.1 & 8 & 5.9 & 135 & \\
\hline Primary & 211 & 96.3 & 8 & 3.7 & 219 & \\
\hline Secondary and more & 42 & 91.3 & 4 & 8.7 & 46 & \\
\hline
\end{tabular}

p-values obtained from Chi-Squire test

area, transportation and communication systems are not well developed, and the means of transportation available for going to the healthcare institutions such as boats and rickshaws are very limited. Within this adverse geographic location, it was observed that mothers who had higher educational attainment were far more likely

Table 7 Percentage of the respondents received postnatal care by some socio-economic and demographic factor

\begin{tabular}{|c|c|c|c|c|c|c|}
\hline \multirow[t]{3}{*}{ Background characteristics } & \multicolumn{4}{|c|}{ Postnatal care received } & \multirow{3}{*}{$\begin{array}{l}\text { Total } \\
\mathrm{N}\end{array}$} & \multirow[t]{3}{*}{$p$-value } \\
\hline & \multicolumn{2}{|c|}{ Yes } & \multicolumn{2}{|l|}{ No } & & \\
\hline & $\mathrm{N}$ & $\%$ & $\mathrm{~N}$ & $\%$ & & \\
\hline \multicolumn{7}{|l|}{ Mother's age at birth } \\
\hline Young aged mother $(\leq 25)$ & 29 & 21.8 & 104 & 78.2 & 133 & 0.506 \\
\hline Old aged mother $(>25)$ & 50 & 18.7 & 217 & 81.3 & 267 & \\
\hline \multicolumn{7}{|l|}{ Mother's education } \\
\hline No education & 22 & 14.6 & 129 & 85.4 & 151 & \\
\hline Primary & 46 & 22.7 & 157 & 77.3 & 203 & 0.126 \\
\hline Secondary and more & 11 & 23.9 & 35 & 76.1 & 46 & \\
\hline \multicolumn{7}{|l|}{ Husband's education } \\
\hline No education & 20 & 14.8 & 115 & 85.2 & 135 & \\
\hline Primary & 49 & 22.4 & 170 & 77.6 & 219 & 0.208 \\
\hline Secondary and more & 10 & 21.7 & 36 & 78.3 & 46 & \\
\hline
\end{tabular}

p-values obtained from Chi-Squire test
Table 8 Logistic regression estimates for use of antenatal care

\begin{tabular}{|c|c|c|c|c|}
\hline \multirow[t]{2}{*}{ Independent variable } & \multirow{2}{*}{$\begin{array}{l}\text { Regression } \\
\text { coefficient }\end{array}$} & \multirow{2}{*}{$\begin{array}{l}\text { Odds ratio } \\
=\operatorname{Exp}(B)\end{array}$} & \multicolumn{2}{|c|}{$95 \%$ C.I. for $\operatorname{Exp}(B)$} \\
\hline & & & Lower & Upper \\
\hline \multicolumn{5}{|l|}{ Mother's age at last birth } \\
\hline Less than 25 years (RC) & & 1.00 & & \\
\hline 25 years and more & -0.390 & 0.677 & .372 & 1.232 \\
\hline \multicolumn{5}{|l|}{ Birth order } \\
\hline First birth (RC) & & 1.00 & & \\
\hline Second birth and more & -0.414 & 0.661 & .333 & 1.314 \\
\hline \multicolumn{5}{|l|}{ Mother's education } \\
\hline No education (RC) & & 1.00 & & \\
\hline Primary & 1.248 & $3.378^{*}$ & 1.394 & 8.696 \\
\hline Secondary and more & 1.217 & $3.482^{*}$ & 1.495 & 7.631 \\
\hline \multicolumn{5}{|l|}{ Husband's education } \\
\hline No education (RC) & & 1.00 & & \\
\hline Primary & 0.888 & 2.429 & .984 & 6.001 \\
\hline Secondary and more & 0.576 & 1.779 & 0.825 & 3.839 \\
\hline \multicolumn{5}{|l|}{ Monthly family income } \\
\hline Less than Tk. 2500 (RC) & & 1.000 & & \\
\hline TK. 2500 and more & .084 & 1.087 & 0.657 & 1.799 \\
\hline \multicolumn{5}{|l|}{ Occupation of husband } \\
\hline Laborer (RC) & & 1.000 & & \\
\hline Other than laborer & 0.488 & 1.630 & .932 & 2.849 \\
\hline Constant & -1.092 & .336 & & \\
\hline \multicolumn{5}{|c|}{ HosmerLomshow test $=$ Chi-square 7.942 sig. 0.439} \\
\hline \multicolumn{5}{|l|}{-2 Log likelihood $=466.256$} \\
\hline Nagelekerke R. $=.188$ & & & & \\
\hline
\end{tabular}

${ }^{*}=p<0.05, R C$ reference category

to use ANC. However, the education level of the mothers' in the study area was very low compared to the national average [1].

Delivery care is another component of MHC, which is assessed by the place of delivery and assistance during the delivery. The percentage of deliveries at healthcare facilities in the study area was approximately half the national average for rural areas [3]. Deliveries attended by untrained traditional birth attendants were higher than the national average of $62.5 \%$. Postnatal check-ups provide an opportunity to assess and treat delivery complications and to counsel mothers on how to care for themselves and their newborns. Younger women, educated mothers and mothers who have husbands with higher education levels received more PNC. The percentage of women and infants who received PNC was also much lower than the national average. National statistics show that $29 \%$ of women and $30 \%$ of children received PNC from medically trained providers within 42 days after delivery [3]. A number of factors contribute to not seeking PNC, including lack of money, lack of 
Table 9 Logistic regression estimate for place of delivery of respondents

\begin{tabular}{|c|c|c|c|c|}
\hline \multirow[t]{2}{*}{ Independent variable } & \multirow{2}{*}{$\begin{array}{l}\text { Regression } \\
\text { coefficient }\end{array}$} & \multirow{2}{*}{$\begin{array}{l}\text { Odds ratio } \\
=\operatorname{Exp}(\mathrm{B})\end{array}$} & \multicolumn{2}{|c|}{$95 \%$ C.I. for $\operatorname{Exp}(B)$} \\
\hline & & & Lower & Upper \\
\hline \multicolumn{5}{|l|}{ Mother's age at last birth } \\
\hline Less than 25 years (RC) & & 1.00 & & \\
\hline 25 years and more & -1.436 & $0.24^{*}$ & 0.059 & 0.954 \\
\hline \multicolumn{5}{|l|}{ Birth order } \\
\hline First birth (RC) & & 1.00 & & \\
\hline Second birth and more & -0.971 & 0.379 & 0.115 & 1.251 \\
\hline \multicolumn{5}{|l|}{ Family type } \\
\hline Nuclear family (RC) & & 1.00 & & \\
\hline Extended family & -0.920 & 0.399 & 0.135 & 1.181 \\
\hline Constant & 4.314 & 74.725 & & \\
\hline \multicolumn{5}{|c|}{ HosmerLomshow test $=$ Chi-square 5.73, sig. 0.125} \\
\hline \multicolumn{5}{|l|}{-2 Log likelihood = 133.33} \\
\hline Nagelekerke $R_{.}=.188$ & & & & \\
\hline
\end{tabular}

need of the PNC services, prohibitive cost, transportation problems, etc. The majority of the respondents (85\%) opined that regular check-ups were not needed. This implies that they do not seek any care if they do not face any problem. However, we know from the literature that postnatal visits should be made within two days after giving birth [24]. Bivariate analysis of receiving

Table $\mathbf{1 0}$ Logistic regression estimates for assistance at delivery of respondents

\begin{tabular}{|c|c|c|c|c|}
\hline \multirow[t]{2}{*}{ Independent variable } & \multirow{2}{*}{$\begin{array}{l}\text { Regression } \\
\text { coefficient }\end{array}$} & \multirow{2}{*}{$\begin{array}{l}\text { Odds ratio } \\
=\operatorname{Exp}(\mathrm{B})\end{array}$} & \multicolumn{2}{|c|}{$95 \%$ C.I. for $\operatorname{Exp}(\mathrm{B})$} \\
\hline & & & Lower & Upper \\
\hline \multicolumn{5}{|l|}{ Mother's age at last birth } \\
\hline Less than 25 years (RC) & & 1.00 & & \\
\hline 25 years and more & 0.009 & 1.009 & 0.475 & 2.142 \\
\hline \multicolumn{5}{|l|}{ Birth order } \\
\hline First birth (RC) & & 1.00 & & \\
\hline Second birth and more & 0.626 & 1.871 & 0.832 & 4.208 \\
\hline \multicolumn{5}{|l|}{ Family type } \\
\hline Nuclear family (RC) & & 1.00 & & \\
\hline Extended family & 0.057 & 1.059 & .438 & 2.558 \\
\hline \multicolumn{5}{|l|}{ Mother's education } \\
\hline No education (RC) & & 1.00 & & \\
\hline Primary & -.783 & $0.457^{*}$ & 0.179 & 0.948 \\
\hline Secondary and more & -0.887 & $0.412^{*}$ & 0.216 & 0.968 \\
\hline Constant & -1.024 & .359 & & \\
\hline \multicolumn{5}{|c|}{ HosmerLomshow test $=$ Chi-square 1.72 , sig. 0.786} \\
\hline \multicolumn{5}{|l|}{-2 Log likelihood $=357.33$} \\
\hline Nagelekerke $R_{.}=0.056$ & & & & \\
\hline
\end{tabular}

PNC and different socio-economic and demographic factors revealed that only variables like mother's age at birth, mother's education, and husband's level of education were significantly associated with receiving PNC.

\section{Limitations}

There are several limitations of the present study. While conducting the interviews, we had to depend on the information provided by mothers. Information could, thus, have been subject to recall bias. However, we were careful in collecting the data they provided and in the analysis and interpretation of the results. The findings are only generalizable to the haor areas since the studied socio-demographic and economic characteristics are different from the populations in other parts of the country.

\section{Conclusions}

The utilization of MHC in the haor area is below the standard level. The status of main indicators of MHC utilization such as receiving ANC from medically trained providers, giving birth at a health facility, delivery assisted by medically trained providers, receiving PNC for mother and new-born baby from medically trained providers, are all below the national average. Only mothers' education and mothers' age at last birth influenced the utilization of ANC, birth facilities, and the use of trained providers. In this study, mothers' age at birth, birth order, mothers' education, husbands' education, family type, and family income were found to be associated with MHC utilization. Improved MHC utilization can reduce maternal mortality and maternal morbidity. To achieve the Sustainable Development Goal (SDG) 3.1, MHC utilization must be improved in remote parts of the country. The study, therefore, concludes that the Bangladesh government needs to act deliberately to address the factors responsible for the observed MHC utilization differential in haor areas compared to other regions of the country.

\section{Endnotes \\ ${ }^{1}$ Lowest administrative unit in Bangladesh.}

\begin{abstract}
Abbreviations
ANC, antenatal care; DGFP, directorate general of family planning; DGHS, directorate general of health services; ESP, essential service package; GO, government organization; MBBS, bachelor of medicine and bachelor of surgery; MDG, millennium development goals; $\mathrm{MHC}$, maternal health care; MMR, maternal mortality ratio; MOHFW, ministry of health and family welfare; NGO, non-government organization; PNC, post-natal care; SDG, sustainable development goals; SMPP, safe motherhood promotion project
\end{abstract}

\section{Acknowledgements}

The authors are thankful to the Department of Population Sciences, University of Dhaka and the United Nations Population Fund (UNFPA), Bangladesh for supporting the study. We are also grateful to all the families who contributed directly and indirectly to the study. We wish to thank Drs. Mary Shaw and Kalai Mathee, Professor at Florida International University for 
their very helpful advice in revising the manuscript. We are thankful to Jeanette Garcia, Graduate Consultant, Writing Centre, and Florida International University for her help in copy editing. The authors are also thankful to Mr. Michael Jones for copy editing the manuscript. We are also thankful to the editor and reviewers for their valuable comments and suggestion which led to significant improvements of the manuscript.

\section{Funding}

UNFPA Bangladesh had a joint funding collaboration with the Department of Population Sciences and Mr. Das received a merit scholarship of US $\$ 1000.00$ for conducting the study.

\section{Availability of data and materials}

Dataset and other material used in this article can be accessed by request to the lead author.

\section{Authors' contributions}

MAH: Had the original idea for the study, planned the study, drafted the manuscript, revised it critically for important intellectual content, handled supervision of overall work, and final approval of the version to be submitted. SKD: Helped in data collection, analysed the data, and drafted the manuscript. MABC: Revised critically for important intellectual content, helped in statistical interpretation, contributed in addressing reviewers' comments, and final approval of the version to be submitted. All authors read and approved the final manuscript.

\section{Competing interests}

The authors declare that they have no competing interests.

\section{Consent for publication}

The results have been approved for publication by The Research Evaluation Board and Academic Committee of the Department of Population Sciences, University of Dhaka, Bangladesh. Also, the manuscript does not contain any identifiable individual data including individual details, images or video.

\section{Ethics approval and consent to participate}

Ethical approval and consent to conduct the study was approved by The Research Evaluation Board and Academic Committee of the Department of Population Sciences, University of Dhaka, Bangladesh. Informed consent was received from the study participants before enrolling them in the study.

\section{Author details}

'Department of Population Sciences, University of Dhaka, Dhaka 1000 Bangladesh. ${ }^{2}$ Department of Biostatistics, Robert Stempel College of Public Health \& Social Work, Florida International University, Miami, FL 33199, USA.

Received: 27 September 2015 Accepted: 24 June 2016

Published online: 18 July 2016

\section{References}

1. BBS. Report on Sample Vital Registration System (SVRS)-2013. Bangladesh Bureau of Statistics (BBS): Dhaka; 2015.

2. Mitra S, Ali M, Islam S, Cross A, Saha T. Bangladesh Demographic and Health Survey, 2004. NIPORT, Mitra and Associates and ORC Macro International Inc. Ministry of Planning 2005.

3. NIPORT, Evaluation M, ICDDR B. Bangladesh Demographic and Health Survey (BDHS) 2011. 2012

4. Safe Motherhood Promotion Project (SMPP) [http://www.carebangladesh.org/ publication/Publication_1114025.pdf]. Accessed 13 Jul 2016.

5. NIPORT, Evaluation; M, ICDDR B. Bangladesh Maternal Mortality and Health Care Survey 2010. Dhaka: NIPORT, MEASURE Evaluation, and ICDDR,B; 2012.

6. BBS. Health and Morbidity Status Survey 2012. Bangladesh Bureau of Statistics (BBS): Dhaka; 2013.

7. NIPORT, Associaltes; Ma, Macro O. Bangladesh Demographic and Health Survey 2004. Dhaka: National Institute of Population Research and Training, Mitra and Associates, and ORC Macro; 2005

8. Starrs AM. Safe motherhood initiative: 20 years and counting. Lancet. 2006; 368(9542):1130-2

9. UN. United Nations Millennium Declaration: Resolution. United Nations (UN); 2000. http://www.un.org/millennium/declaration/ares552e.pdf. Accessed 5 Jan 2016
10. GoB GB. Millennium Development Goals: Bangladesh Progress Report 2013. Dhaka: Planning Commission Government of the People's Republic of Bangladesh; 2014.

11. Bangladesh BU. Progotir Pothe: Multiple Indicator Cluster Survey 2012-13. Dhaka: Bangladesh Bureau of Statistics and UNICEF Bangladesh; 2014.

12. GED. Millennium Development Goals: Bangladesh Progress Report 2013. Dhaka: Support to Sustainable and Inclusive Planning (SSIP) Project, General Economics Division, Planning Commission. Government of the People's Republic of Bangladesh \& UNDP Bangladesh; 2014.

13. Khan KS, Wojdyla D, Say L, Gülmezoglu AM, Van Look PF. WHO analysis of causes of maternal death: a systematic review. Lancet. 2006;367(9516):1066-74.

14. Starrs A. The safe motherhood action agenda: priorities for the next decade. Proceedings. The Washington, DC: World Bank; 1997. http://documents. worldbank.org/curated/en/1997/10/442078/safe-safemotherhood-actionagenda-priorities-next-decade.

15. Stanton CK. Methodological issues in the measurement of birth preparedness in support of safe motherhood. Eval Rev. 2004;28:179-200. doi:10.1177/0193841X03262577.

16. Miller S, Sloan NL, Winikoff B, Langer A, Fikree FF. Where is the "E" in MCH? The need for an evidence-based approach in safe motherhood. J Midwifery Womens Health. 2003;48(1):10-8. doi:10.1016/\$1526-9523(02)00369-0.

17. Moran AC, Winch PJ, Sultana N, Kalim N, Afzal KM, Koblinsky M, Arifeen SE, Seraji MHR, Mannan I, Darmstadt GL, Baqui, AH; The Bangladesh PROJAHNMO Maternal Morbidity Study Group. Patterns of maternal care seeking behaviours in rural Bangladesh. Tropical Med Int Health. 2007;12: 823-32. doi:10.1111/j.1365-3156.2007.01852.x

18. Macro O. Bangladesh Maternal Health Services and Maternal Mortality Survey, 2001. Dhaka, Bangladesh: National Institute of Population Research and Training (NIPORT); 2003

19. Chakraborty N, Islam MA, Chowdhury RI, Bari W, Akhter HH. Determinants of the use of maternal health services in rural Bangladesh. Health Promot Int 2003;18(4):327-37

20. Vasudevan L, Labrique AB, Mehra S, Wu L, Levine O, Feikin D, Klemm R, Christian P, West Jr KP. Maternal determinants of timely vaccination coverage among infants in rural Bangladesh. Vaccine. 2014:32(42):5514-9.

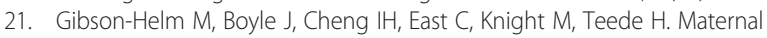
health and pregnancy outcomes among women of refugee background from Asian countries. Int J Gynecol Obstet. 2015;129(2):146-51.

22. Campbell OMR, Graham WJ. Strategies for reducing maternal mortality: getting on with what works. Lancet. 2006;368(9543):1284-99.

23. El Arifeen S, Hill K, Ahsan KZ, Jamil K, Nahar Q, Streatfield PK. Maternal mortality in Bangladesh: a Countdown to 2015 country case study. Lancet. 2014:384(9951):1366-74.

24. WHO. Pregnancy, childbirth, postpartum and newborn care: a guide for essential practice and essential newborn care course. Geneva: WHO; 2010.

\section{Submit your next manuscript to BioMed Central and we will help you at every step:}

- We accept pre-submission inquiries

- Our selector tool helps you to find the most relevant journal

- We provide round the clock customer support

- Convenient online submission

- Thorough peer review

- Inclusion in PubMed and all major indexing services

- Maximum visibility for your research

Submit your manuscript at www.biomedcentral.com/submit 